\title{
Abrimos el telón al Teatro Clásico Español en la clase de E/LE
}

LUC C. SOUTO

Universitat de València

luz.souto@uv.es

\begin{abstract}
Resumen: El siguiente artículo busca llevar el Teatro Clásico Español a los estudiantes de Español como Lengua Extranjera. Se propone, en primer lugar, un recorrido por los espacios teatrales del Siglo de Oro, deteniéndonos, especialmente, en los corrales de comedia. Desde allí, se continúa con la transformación que realizó el dramaturgo Lope de Vega y se plantean diferentes actividades en torno a la comedia La viuda valenciana. Finalmente, como cierre de telón del estudio, se formula una representación teatral en la que los estudiantes se sientan partícipes de la práctica escénica y de la cultura y la lengua española.
\end{abstract}

Palabras clave: Siglo de Oro, Teatro Clásico Español, clase de E/LE, Lope de Vega Spanish Classical Theater in E/LE class

Abstract: The present article tries to bring the Spanish Classical Theater to students of Spanish as a Foreign Language. It is proposed, first of all, a tour of the theatrical spaces of the Spanish Golden Age, paying attention, especially, in the «corrales de comedia». It continues with the transformation made by Lope de Vega, and different activities are proposed around La viuda valenciana. Finally, a theatrical representation is formulated in which the students feel that they are taking part of the scenic practice and of the Spanish culture and language.

Key words: Spanish Golden Age, Spanish Classical Theater, Spanish as a Foreign Language, Lope de Vega

\section{Preludio}

El presente trabajo tiene como objetivo una aproximación al Teatro Clásico Español en el aula de E/LE. Esta propuesta entronca con la experiencia práctica esbozada en Souto (2017). En el artículo anterior se abordó el concepto de clásico y una novela en concreto, Don Quijote de la Mancha, ahora se continúa el recorrido por los clásicos españoles centrándonos en el teatro áureo.

Cabe destacar que la propuesta no se basará solamente en actividades y herramientas para la lectura del teatro clásico, sino que se propone también como un recorrido por la cultura española del Siglo de Oro. La finalidad es la inmersión de los estudiantes en la lengua española por medio de un enfoque por tareas, así, el objetivo principal será crear un espacio de comunicación en el aula, guiado por una acción dialógica (Freire 1970) y apoyado en actividades conjuntas que introducirán un aspecto lúdico al aprendizaje. Tal es el caso de la propuesta final del itinerario, que será una representación teatral. 
Así, a medida que los alumnos se adentren en la historia y distingan los diferentes espacios teatrales del Siglo de Oro, experimentarán una aproximación a las obras en verso, se sumergirán en la cultura española $\mathrm{y}$, a la vez, podrán ir adquiriendo o perfeccionando el idioma. Sobre todo, debemos tener en cuenta que recitar versos puede servir para perfeccionar la pronunciación y desarrollar con mejor precisión la entonación y los recursos expresivos del español.

La experiencia práctica se desarrollará a partir de la lectura de fragmentos de La viuda valenciana, y estará dirigida especialmente a alumnos/as de los niveles B1/B2, C1/C2, no obstante, se propondrán también actividades adaptables para los cursos iniciales. Es sabido que el Teatro Clásico Español tienen ventajas y desventajas en el momento de su trasmisión en una case de E/LE. Las problemáticas, creo, están muy claras para muchos profesores: los cultismos, los aspectos gramaticales, el verso, la comprensión textual y, muchas veces, la preferencia de los alumnos, que están más acostumbrados a la lectura de otros géneros, como el cuento o, muchas veces, lamentablemente, no habituados a poner en práctica el músculo lector. No obstante, para poder acercar a ellos el patrimonio teatral clásico ya contamos con un gran arsenal de posibilidades didácticas que, como he comentado, serán adaptables para las distintas etapas.

\section{El Teatro Clásico Español y sus espacios}

Para una introducción al Siglo de Oro, una posibilidad es iniciar nuestra propia inmersión, como profesores, con los materiales propuestos por el Ministerio de Educación, Cultura y Deporte para el nivel B21, que aunque acuden a estereotipos, pueden darnos las directrices básicas para solventar los primeros pasos. También se puede comenzar por la noción de "clásico", ya abordada en Souto (2017), disponible en el número 13 de Foro de Profesores de E/LE. Para un análisis más específico y para la preparación docente se recomiendan los capítulos dedicados al teatro incluidos en las historias de la literatura, tales como López Estrada (1980), Egido Martínez (1983), Arellano (1995), Huerta Calvo (2003), Ruiz Pérez (2010).

Para el caso preciso del Teatro Clásico Español, mi propuesta es recuperar, primero, los espacios teatrales más característicos del Siglo de Oro: los corrales de comedia, la Corte y el espacio urbano, este último ligado a los autos sacramentales. También podemos abordar los representantes y el público, la figura de los mosqueteros, por ejemplo, suele ser fácilmente identificable e interesante para los estudiantes. A modo de síntesis de las posibilidades presento el siguiente cuadro:

\footnotetext{
${ }^{1}$ Disponible en https://www.mecd.gob.es/francia/dms/consejeriasexteriores/francia/publicaciones/material-didactico/Materiales-ELE/2013/materialesele2013b2.pdf [Recuperado 3/3/2018].
} 


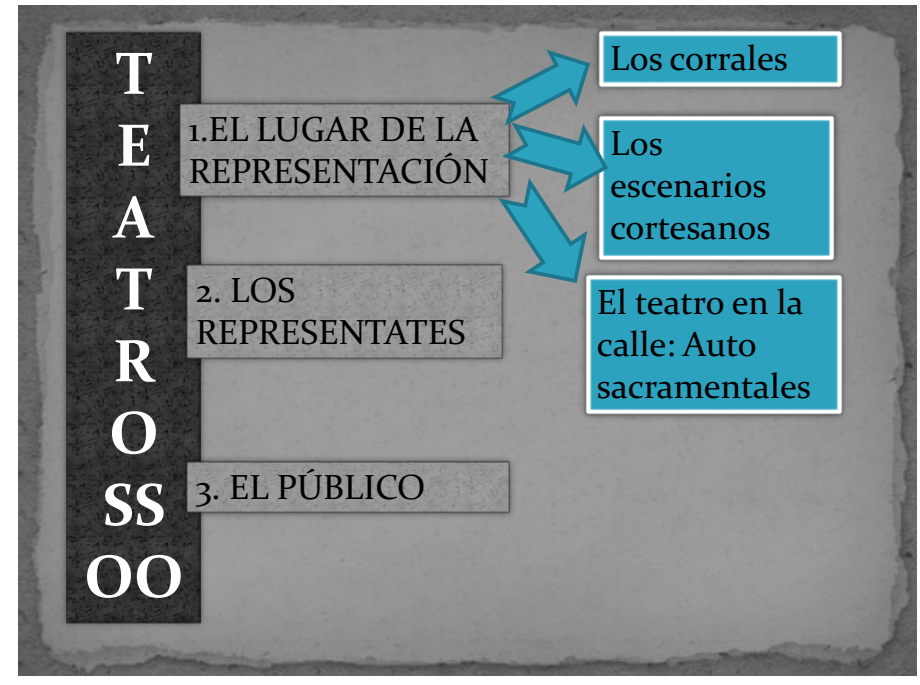

Figura 1. Principales elementos del teatro del Siglo de Oro

Para la bibliografía específica sobre los espacios de la representación puede acudirse a Arellano (2005), Díez Borque (1991), o a recursos digitales realizados por especialistas, como es el caso de El teatro clásico español a través de sus documentos: materiales docentes multimedia ${ }^{2}$, efectuado por el grupo de innovación educativa Te@doc, coordinado por la Dra. Teresa Ferrer Valls. Hay que mencionar que, además de la información contrastada que servirá como guía de trabajo, en la web se podrán encontrar vídeos, imágenes, documentos y actividades para cada apartado.

También es de gran interés para los profesores el portal Ars Theatrica. Siglos de Oro ${ }^{3}$, coordinado por la Dra. Evangelina Rodríguez Cuadros. Ambas páginas ponen a disposición de los profesores herramientas docentes de acceso gratuito, surgidas de grupos de investigación de excelencia en el estudio del Siglo de Oro, avalados por proyectos de $\mathrm{I}+\mathrm{D}+\mathrm{i}$ del Ministerio de Educación y Ciencia.

\section{Del Siglo de Oro al aula de E/LE}

Ante el ingente panorama de abordaje, propongo centrarnos en el espacio público comercial del teatro áureo, los corrales de comedias. Espacio donde vio representadas gran parte de sus obras uno de los dramaturgos más famosos del Siglo de Oro: Lope de Vega. Los ejemplos que veremos en las próximas páginas serán en base a su obra La viuda valenciana. Para la lectura en impreso se recomienda la publicación de Clásicos Castalia y para la lectura en digital la versión disponible en la Colección Canon 60 del proyecto de Investigación TC/12. Patrimonio Teatral Clásico Español. Textos e Instrumentos de Investigación ${ }^{4}$. Ambas ediciones han estado al cuidado de la especialista Teresa Ferrer Valls.

\subsection{Introducción a los corrales de Comedias}

\footnotetext{
${ }^{2}$ Disponible en http://dicat.uv.es/te@doc/el_teatro_y_sus_documentos.html [Recuperado 1/4/2018].

${ }^{3}$ Disponible en http://parnaseo.uv.es/Ars/ARST6/index.html\# [Recuperado 1/4/2018].

${ }^{4}$ Disponible en http://tc12.uv.es/canon60/C6054_LaViudaValenciana.php [Recuperado 1/4/2018].
} 
Como actividad introductoria explicaremos las diferentes características de los corrales de comedias y desgajaremos el léxico correspondiente: desvanes, aposentos, gradas, bancos, cazuela, alojero, escenario, vestuario, escotillón, tramoya, público, actores, etc. La selección de vocabulario puede realizarse de acuerdo al nivel. El más sencillo y actual para los cursos A1, A2 (escenario, vestuario, público) y el específico para B1, $\mathrm{B} 2, \mathrm{C} 1, \mathrm{C} 2$.

\section{Actividad 1}

Los diseños de las diferentes partes del Corral de comedias pueden utilizarse a modo de fichas. Una vez que se haya explicado cada nombre, circularán las imágenes y los alumnos deberán indicar la nomenclatura correspondiente ${ }^{5}$ que estará en una ficha diferente. Un ejemplo basado en el teatro de Almagro:
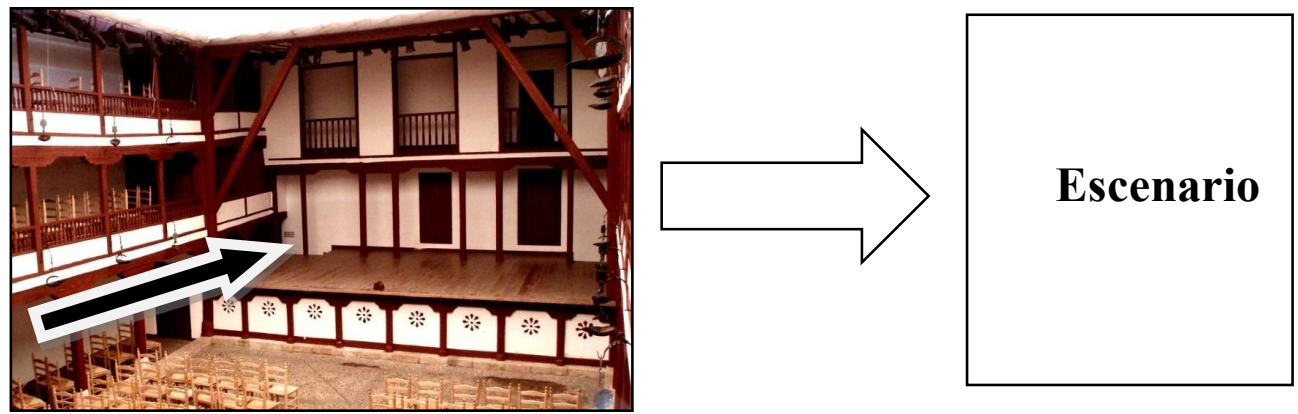

Figura 2. Corral de Comedias de Almagro

\section{Actividad 2}

Proyectaremos una reconstrucción virtual de un corral de comedias. Dos ejemplos que pueden ser utilizados son el Corral de la Montería de Sevilla y El patio de las Arcas de Lisboa $^{6}$. Luego de la visualización trabajaremos las diferencias en la distribución del espacio con los teatros que los estudiantes conocen, ya sea porque han asistido o porque los han visto por medio de películas o series. Este ejercicio puede ser adaptado a los diferentes niveles para trabajar comprensión auditiva y expresión oral. En los parámetros de A1 y A2 se recomienda no ver la reconstrucción virtual completa y que el profesor explique las características principales. Las preguntas orientativas para trabajar la destreza oral son:

(1) ¿Con qué frecuencia van al teatro?

(2) ¿Qué puesta en escena vieron por última vez?

(3) ¿Qué obras clásicas españolas, inglesas, italianas o francesas pueden nombrar?

5 Para la documentación visual puede visitarse la ya mencionada Ars Theatrica Siglos de Oro $<$ http://parnaseo.uv.es/Ars/ARST6/index.html\#>, [Recuperado 03/5/2018].

${ }^{6}$ Ambas reconstrucciones virtuales han sido realizadas por el grupo de Investigación Teatro del Siglo de Oro de la Universidad de Sevilla (Piedad Bolaños, Mercedes de los Reyes, Vicente Palacios, Juan Ruega). En la reconstrucción del Patio de las Arcas se suma el investigador José Camões de la Universidade de Lisboa. Información y vídeos disponibles en http://investigacionteatrosiglodeoro.com/?page_id=269 http://investigacionteatrosiglodeoro.com/?page_id=281 [Recuperado 25/4/2018]. 


\section{Actividad 3}

Otra actividad posible a partir de los corrales de comedia es el trabajo de expresión oral donde se acentúen la argumentación y la comparación de dos elementos. Partiremos de dos imágenes, una de los correales de comedias y la otra de un teatro actual. Luego de la visualización solicitaremos a los estudiantes que respondan, individualmente, las siguientes preguntas:

(1) ¿Cómo son los techos de uno y de otro teatro?

(2) ¿Cómo piensan que era la iluminación en los corrales de comedias?

(3) ¿Dónde se sentaban las mujeres y dónde los hombres?

(4) ¿Cómo es la distribución del espacio teatral en la actualidad?

\section{Introducción a Lope de Vega}

Continuaremos el recorrido con una breve introducción a la figura de Lope de Vega, destacando la transformación que el dramaturgo ejerció en las tablas. Para un acercamiento a su semblanza y a las características de su Arte nuevo de hacer comedias puede acudirse a Pedraza (2009). Se buscará, igualmente, llegar a los alumnos destacando la importancia del Fénix de los ingenios en el patrimonio cultural español. A fin de despertar el interés pueden mostrarse ejemplos de su vigencia también en la cultura actual a través de películas como Lope (Waddington, 2010), series televisivas como Cervantes contra Lope y El ministerio del tiempo, o puestas en escenas como El arte nuevo de hacer comedias en este tiempo de la compañía Micomicón, donde las pautas para la transformación del teatro son recitadas por medio de títeres.

Es este marco donde se sugiere trabajar con una obra en concreto, La viuda valenciana. La selección se debe, sobre todo, al carácter dinámico de la obra, ya que se trata de una divertida comedia urbana. Por otro lado, para aquellos grupos que estudien en Valencia o que tengan pensado viajar a la ciudad, pueden visitar sitios que se nombran en la obra como el «Puente del Real».

\subsection{La viuda valenciana}

Para la lectura en impreso se recomienda la publicación de Clásicos Castalia y para la lectura en digital la versión disponible en la Colección Canon 60 del proyecto de Investigación TC/12. Patrimonio Teatral Clásico Español. Textos e Instrumentos de Investigación. Ambas ediciones han estado al cuidado de la especialista Teresa Ferrer Valls. La lectura se aconseja a partir del nivel B1 y con una selección de fragmentos, en los cursos B2 a C2 puede leerse la obra en su totalidad.

Como ayuda para hacer la inmersión en la obra y guiar la lectura se propone acudir a la Base de Datos Artelope, de la Universitat de València ${ }^{7}$. En la misma se hallará el detalle de los datos bibliográficos, donde se incluyen tanto las ediciones disponibles como la

\footnotetext{
${ }^{7} \mathrm{http}$ //artelope.uv.es/basededatos/browserecord.php?-action=browse \&-recid=364 [Recuperado 27/4/2018].
} 
bibliografía secundaria con la que podemos contar; la caracterización de los personajes, el universo social al que corresponde la comedia, el tiempo histórico, el marco espacial, la duración de los actos, etc. Acompaña el estudio un extracto argumental por cada uno de los tres actos, lo que simplifica el trabajo de interpretación de los estudiantes.

\section{Actividad 4}

Para empaparnos en la obra una posibilidad es instar a los estudiantes a que efectúen una caracterización de los personajes principales. Los más importantes para el avance de la acción son: Camilo, el galán (caballero) y Leonarda, la joven viuda (dama). También son de vital importancia para el humor de la comedia los criados y criadas, en este caso tenemos a Floro, el criado de Camilo; Julia, la criada de Leonarda y Urbán, que es el escudero de Leonarda y desempeña el papel del gracioso.

Con esta actividad trabajaremos las descripciones físicas, así, buscaremos una adquisición de vocabulario más culto para los niveles superiores y adaptado en el caso del alumnado de A1 a B1. Respecto a los cursos iniciales, se recomienda la presentación de la obra por parte de la profesora, incluso, trabajar con los resúmenes y datos de la comedia disponibles en la ya citada Base de Datos Artelope.

\section{Actividad 5}

A partir del personaje de Leonarda trabajaremos la competencia sociolingüística, ya que la figura femenina propuesta por Lope de Vega es de especial riqueza y, por lo tanto, también abre muchas posibilidades para el desarrollo de actividades. Leonarda es, desde los primeros versos, una mujer que lee, que decide quedarse sola cuando ha quedado viuda y, finalmente, es ella quien elige al caballero, Camilo. Es decir, toma como suyo el lugar de galán y de conquistadora. Por ello, esta dama nos dará la excusa para que los estudiantes describan el papel de la mujer en la sociedad actual.

La propuesta de trabajo puede partir del análisis del profesor sobre las características más atípicas de Leonarda en el contexto del Siglo de Oro y solicitar a los estudiantes una redacción sobre el lugar de la mujer en la sociedad actual. La redacción puede adaptarse al nivel de cada grupo y, en caso de que se trate de un A1 o A2 la redacción no pasará las 80-100 palabras, el léxico será básico, las frases simples y el tiempo presente.

\section{Actividad 6}

Esta obra, permite, además, trabajar con el léxico ligado al carnaval y al ocultamiento. La acción transcurre en Valencia y durante la fiesta de carnaval, este enclave permitirá a la protagonista, Leonarda, ocultar su identidad y recibir por la noche al galán, Camilo. Dado que utilizaremos una edición digital, se puede solicitar a los estudiantes que hagan búsquedas de palabras clave asociadas al carnaval y a la trama de la comedia. Los alumnos leerán los versos en que aparecen las siguientes palabras y a continuación se realizará un trabajo de sinónimos y antónimos. Ejemplo:

(1) Máscara / enmascarado/ engaño/ ojos/ cubrir / ciego /

Claridad / luz / velas /desvelado/ rostro /semblante 
En este caso, los versos que acompañan el campo semántico son:

CAMILO ¿Qué es esto?

¿Todos con máscara están?

LEONARDA Tened las manos, galán;

que aquí no ha de haber más que esto.

En llegando a querer verme,

os harán dos mil pedazos.

CAMILO En tal sagrado de brazos

no podrán acometerme.

No por su miedo -ipor Dios!

que, pues vine, no le tuve-,

mano y deseos detuve,

mas por mandármelo vos.

¡Qué bello cuerpo tenéis!

¿Qué traje y rico vestido!

Con razón no he merecido

que en mi bajeza fiéis.

¡Bravas telas y brocados!

¡Bravos cuadros y pinturas!

Pero todo queda a escuras

con tales ojos cerrados. (VV. 1332-1350)

\section{Actividad 7}

Para los niveles B2 a C2 es posible visualizar la película realizada por Estudio 1, bajo la dirección Carlos Sedes $^{8}$ en 2010. Puede acompañarse la proyección de los subtítulos en español para permitir una mejor comprensión. Como actividad complementaria al visionado los estudiantes deberán redactar una reseña en la que califiquen la película. La mitad del grupo deberá recomendar el film de manera positiva y la otra mitad de manera negativa. Luego se expondrá el trabajo. Con ello trabajaremos la argumentación.

\section{Actividad 8}

La última actividad propuesta es, quizás, la que más ilusión trasmitirá a los estudiantes. Y un buen cierre después del entrenamiento de los 7 primeros ejercicios. Se trata de un taller de teatro que se elaborará durante todo el curso, esto permitirá que los alumnos/as se sientan involucrados activamente y que vean su propia evolución en la lengua y la cultura española.

Cabe destacar que en el Marco Común Europeo de Referencia para las lenguas: aprendizaje, enseñanza y evaluación (MCERL) ${ }^{9}$ se recomienda «representar obras de teatro con guion o sin él» y «presenciar y escenificar textos literarios como, por ejemplo, leer y escribir textos (relatos cortos, novelas, poesía, etc.), representar y presenciar como espectador recitales, obras de teatro y de ópera, etc.» (2002: 60).

Como puede evidenciarse, el arte dramático está contemplado en su uso «imaginativo y artístico de la lengua», y a esa utilización apelaremos para trasmitir fragmentos del

\footnotetext{
${ }^{8}$ Disponible en http:/www.rtve.es/alacarta/videos/estudio-1/estudio-1-viuda-valenciana-20101228-2206169/975755/ [Recuperado 8/4/2018].

${ }^{9}$ Disponible en https://cvc.cervantes.es/ensenanza/biblioteca_ele/marco/cvc_mer.pdf [Recuperado $22 / 4 / 2018]$.
} 
teatro clásico español. Ahora bien, es importante introducir poco a poco la actividad y no obligar a que todos representen un papel, ya que puede ser que haya estudiantes más tímidos. En esos casos, dado que la práctica teatral no solamente se basa en la actuación propondremos otros aspectos para llevar adelante la puesta en escena. Estas tareas van desde ser autores, en el sentido del Siglo de Oro, es decir, dirigir la puesta en escena de sus compañeros, hasta trabajar en el decorado y el vestuario. Para aquellos que realicen las actividades complementarias a la actuación final, deberán hacer una exposición oral, previa a la obra, en la que comenten el proceso y utilicen el vocabulario aprendido durante el curso, referentes al escenario, la tramoya o la vestimenta.

No obstante, convendría que todo el grupo se sumara a las técnicas propias de la práctica teatral, tales como relajación y/o activación. Dependiendo de humor con el que lleguen los alumnos y de la actividad que tengamos planeada para ese día, buscaremos que los estudiantes se calmen o se activen por medio de ejercicios físicos. Otras de las técnicas teatrales que ayudarán a la clase de E/LE son las prácticas de concentración, memorización y vocalización.

Para trabajar la dicción y vocalización, en primer lugar, se puede comenzar con parejas de palabras que se diferencian por un fonema: cero, cerro / tasa, taza / bata, pata / día, tía / guiso, quiso / coral, corral / sima, cima / van, pan / deja, teja / gol, col ${ }^{10}$, al comienzo se trabajarán con fichas con los nombres, luego con fichas solo con dibujo a fin de que los alumnos reconozcan las diferentes palabras con sus significados y comiencen a memorizar.

En segundo lugar, se utilizarán versos cortos de La viuda valenciana para que repitan y vayan ejercitando la pronunciación. Como ejemplo, los versos 85 a 88 .

JULIA ¿Que, en fin, no te casarás?

LEONARDA ¡Jesús, Julia, no lo nombres!

Asco me ponen los hombres;

no me los nombres jamás.

Finalmente, en los niveles superiores, se practicará con intervenciones de los personajes más largas. Como, por ejemplo, el famoso parlamento de Leonarda en el que enuncia los motivos para no volver a contraer matrimonio.

La viudez casta y segura, ¿no es de todos alabada?

Si es de la invidia infamada, este engaño poco dura;

(...)

No, sino venga un mancebo

de estos de ahora, de alcorza, con el sombrerito a orza, pluma corta, cordón nuevo, cuello abierto muy parejo, puños a lo veneciano, lo de fuera limpio y sano, lo de dentro sucio y viejo; botas justas, sin podellas

${ }^{10}$ En el caso de que sea necesario profundizar en fonética, se pueden utilizar recursos como los disponibles en http://soundsofspeech.uiowa.edu/resources/spanish/spanish.html [Recuperado 23/4/2018]. 
descalzar en todo un mes,

las calzas hasta los pies,

el bigote a las estrellas;

(...)

los tres mil de renta pesque,

con que un poco se refresque

entre sábanas delgadas;

y pasados ocho días,

se vaya a ver forasteras,

o en amistades primeras

vuelva a deshacer las mías!

Vendrá tarde; yo estaré

celosa; dará mi hacienda;

comenzará la contienda

de esto de si fue o no fue.

Yo esconderé y él dará;

buscará deudas por mí;

entrará justicia aquí;

voces y aun coces habrá.

No habrá noche, no habrá día,

que la casa no alborote (vv. 245-286)

\section{Conclusiones}

En resumen, a través de esta serie de actividades, se ha pretendido llevar el Teatro Clásico Español al aula de E/LE. Desde la incursión en los corrales de comedia, pasando por la figura de Lope de Vega y deteniéndonos en una de sus obras, La viuda valenciana. Se trata de una muestra de la capacidad de los clásicos españoles para trabajar todas las competencias lingüísticas del español de manera dinámica. Como cierre del telón a las actividades se ha propuesto incentivar a los estudiantes para que también tengan un acercamiento a una práctica teatral activa en la que se sientan partícipes. Igualmente, el recitado de versos, así como las técnicas teatrales de relajación, activación, concentración, memorización y vocalización, pueden ser una excelente herramienta para mejorar la pronunciación y ayudarlos a detectar problemas fonéticos.

\section{Bibliografía}

Arellano, I. (2005). «Renacimiento y Barroco». En J. Menéndez Peláez (coord.); Historia de la Literatura Española, vol. 11.

Arellano, I. (1995). Historia del teatro español del Siglo XVII. Madrid: Cátedra.

De VegA, L. (2001). La viuda valenciana. En T. Ferrer Valls (editora). Madrid: Castalia.

FreIRE, P. (1970). Pedagogía del oprimido. Madrid: Siglo XXI.

Hidalgo Martín, V. (2012). «El teatro en la clase de ele: dos propuestas de taller». Marco ELE. Revista de Didáctica de Español Lengua Extranjera, 15, Suplemento. Recuperado el 24/3/2018, de: http://marcoele.com/descargas/15/hidalgo_teatro.pdf

Huerta CAlvo, J. (dir.) (2003). Historia del teatro español. Gredos: Madrid. 
LóPez EstradA, F. (ed.) (1980). Siglos de Oro, Renacimiento. En Rico, F. (coord.); Historia y crítica de la literatura española, vol. 2, Tomo 1. Madrid: Crítica.

Egido Martínez, A. (ed.) (1983). Siglos de Oro, Barroco. En F. Rico (coord.); Historia y crítica de la literatura española, vol. 3, Tomo 1. Madrid: Crítica.

SOUTO LARIOS, L. (2017). «En un lugar del aula... De lo que le sucedió a don Quijote en una clase de E/LE». Foro de profesores de E/LE, 13, 259-269

RuIZ PÉreZ, Pedro (2010). El siglo del arte nuevo (1598-1691). En J. Mainer (dir.); De la Historia de la literatura española, vol. 3. Madrid: Crítica.

PEDRAZA JimÉneZ, F. (2009). Lope de Vega. Vida y Literatura. Valladolid: Secretariado de Publicaciones. 